\title{
Histopathological effects of experimental exposure to lead on nervous system in albino female rats
}

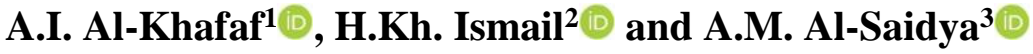 \\ ${ }^{1}$ Department of Biology, College of Education for Girls, ${ }^{2,3}$ Department of Pathology and poultry Diseases, College of \\ Veterinary, University of Mosul, Mosul, Iraq
}

\begin{tabular}{l} 
Article information \\
\hline Article history: \\
Received October 30, 2019 \\
Accepted December 1, 2019 \\
Available online August 20, 2020 \\
\hline Keywords: \\
Histopathology \\
Lead \\
Cerebellum \\
Cerebrum \\
Spinal cord \\
\hline
\end{tabular}

Correspondence:

A.M. Al-Saidya

al2011saidya@gmail.com

\begin{abstract}
Lead toxicity is a common health issue. Lead $(\mathrm{Pb})$ is harmful to vital organs of body particularly the nervous system. This study aimed to estimate the effects of lead on the cerebellum, cerebrum and spinal cord in rat model, focusing on histopathological changes. 24 female mature albino rats of 200-300g randomly divided into 2 groups, the first is the control, and the second group were treated with lead acetate at dose $30 \mathrm{mg} / \mathrm{kg} \mathrm{B}$.W. for 30 days. Microscopic examination revealed degeneration and necrosis of Purkinje cells and molecular cells and decrease in the number of granular cells and molecular cells also observed. Some Purkinje cells lost axons and shrunken and some areas showed depletion of Purkinje cells. Congestion of blood vessels with perivascular cuffing of mononuclear inflammatory cells, hemorrhage, neurophagia, glial nodules were observed in the brain parenchyma. Demyelination reported in white matter, with microglial proliferation around vertebral canal of spinal cord. This study referred to the increased risk of central nervous system damage due to the exposure to lead.
\end{abstract}

DOI: $10.33899 /$ ijvs.2019.126248.1273, (C2020, College of Veterinary Medicine, University of Mosul.

This is an open access article under the CC BY 4.0 license (http://creativecommons.org/licenses/by/4.0/).

\section{Introduction}

Lead is a common environmental and factory-made (heavy metal) contaminant, which cause problem of body health. It is used in many industrial applications such as lead -acid batteries, cosmetics, hair coloring dyes, printing dyes and leaded crystal ware $(1,2)$.

Lead has a noxious effect on organs and tissues especially the brain and peripheral nerves (3). Lead poisoning is a medical condition also known as saturnism or plumbism, it is occurred via oral pathway or less widely via the respiratory pathway or skin (inorganic lead). It affects to the CNS, PNS, kidney, liver, bone marrow, bone, gastrointestinal tract, blood vessels, reproductive and endocrine systems, which appear as acute, subacute or chronic forms (4).

According to (5) exposure to lead is inevitable, and it happens through many ways including contaminated air, water and food. Lead enters the blood circulation and parenchymal tissues and finally to the bones. Lead has a direct effect on enzymes containing sulfhydryl groups, the thiol component of RBCs, antioxidant protection, and mitochondria in many cells, which is observed in the medical condition. Beside to the cerebellar hemorrhage and edema as well as capillary injury, lead is also immune suppressant, nephrotoxic, teratogenic, gametotoxic and noxious to the hematopoietic organs $(6,7)$.

Lead is known to be one of a number of neurotoxins that interfere with and reduced the signaling of ion calcium in nerve processes, also affects many different regions of brain tissue including the cerebral cortex, cerebellum and hippocampus. The damage of blood capillary vessels in the brain cause bleeding and brain swelling. The mechanism by which the nervous signs of encephalopathy and the lesions of peripheral nerve degeneration which appears to be related to the degenerative changes and apoptosis seen in the 
nervous tissue (8). The work of this study aimed to inspect the sequel of exposure to lead acetate on central nervous tissues in rat model, focusing on histopathological changes.

\section{Materials and methods}

The present study was authenticated by scientific committee in the Pathology Department, College of Veterinary Medicine, University of Mosul, Iraq. 24 Female mature albino rats Rattus rattus, of 2.5 months old and body weight of $200-300 \mathrm{~g}$, were separated into two groups. The control group was treated only by physiological salt solution throughout the experiment. The second group was treated with lead acetate orally by intragastric gavage at a dose of 30 $\mathrm{mg} / \mathrm{kg} \mathrm{B}$.W. for 30 days (1).

After the complete of the experiment, rats euthanized by chloroform, after that the brain and spinal cord were collected, and reserved in neutral buffered formalin at $10 \%$ concentration for the preparation of tissue sections. They were impregnated and blocked in paraffin wax, sectioned into5 micron thickness sections, then stained with hematoxylin and eosin stains (9). These sections were then examined for histopathological changes.

\section{Results}

\section{Cerebellum}

Microscopic examination of cerebellum sections of control animals showed normal architecture, which composed of outer molecular layer, inner granular layer cells and in between the single layer of Purkinje cells. Rats treated with lead acetate showed histopathological changes include degeneration and necrosis of Purkinje cells and molecular cells, decrease in the amount of granular cells, Purkinje cells and molecular cells also observed Some Purkinje cells lose axons and shrunken and some areas showed depletion of Purkinje cells, congestion of blood vessels with hemorrhage in molecular layer. Additionally, perivascular cuffing of mononuclear inflammatory cells in the leptomeninges of cerebellum also observed (Figure 1).

\section{Cerebrum}

The Microscopic examination of cerebrum sections showed vasogenic edema, expanded perivascular spaces, and perineuronal edema. Degeneration and necrosis of cortical neurons, with multifocal areas of encephalomalacia. Congestion of blood vessels with perivascular cuffing of mononuclear inflammatory, Additionally, hemorrhage, neurophagia, focal gliosis was observed in the brain paranchyma. Thickening of meninges with congestion of blood vessels and infiltration of inflammatory cells. Also Alzheimer type II astrocytes were observed which characterized by double nuclei which surround by clear space (Figure 2).

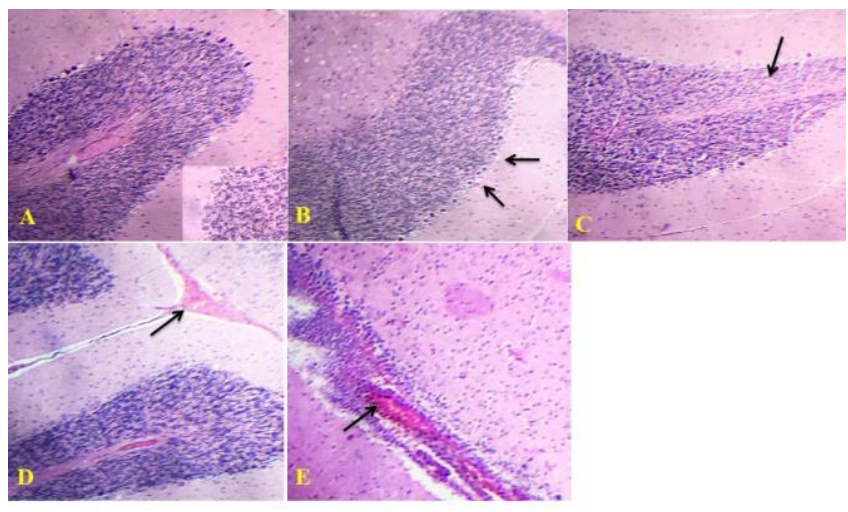

Figure 1: Micrograph of rat brain, treated with lead acetate (A) control group showed normal architecture (H\&E 10x). (B) degeneration and necrosis of Purkinje cells and molecular cells (arrow) (H\&E 40x). (C) decrease in the number of granular, Purkinje and molecular cells (arrow) (H\&E 10x). (D) congestion of blood vessels with hemorrhage seen in molecular layer (arrow) (H\&E 10x). (E) perivascular cuffing of mononuclear inflammatory cells in the leptomeninges of cerebellum (arrow) (H\&E 10x).

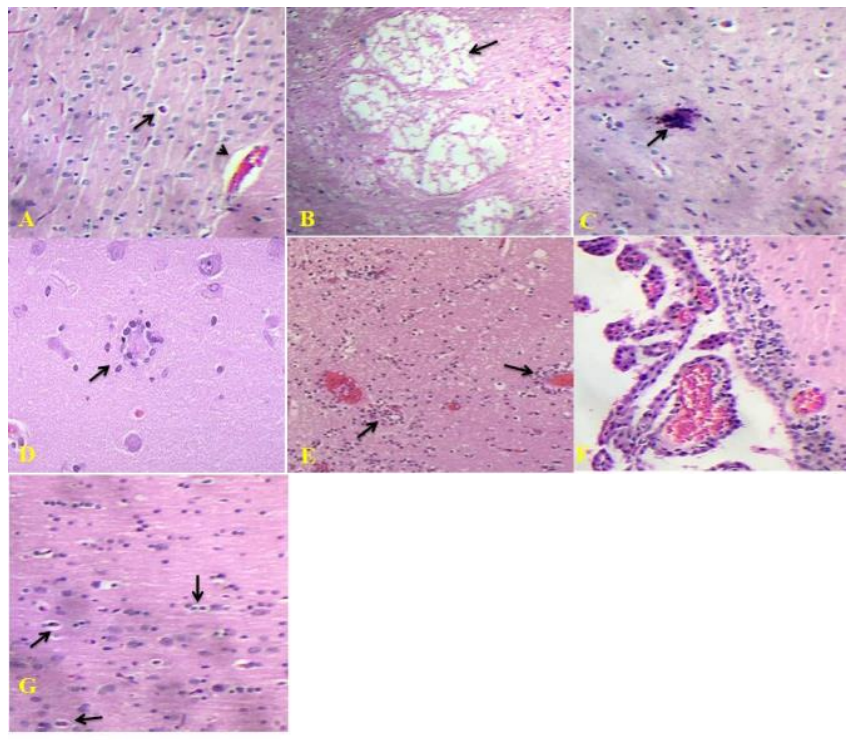

Figure 2: Micrograph of rat brain, treated with lead acetate (A) vasogenic edema, the perivascular space is wide (arrow), also seen around neurons (arrowhead) (H\&E 40x). (B) degeneration and necrosis of cortical neurons, with multifocal areas of encephalomalacia (arrow) (H\&E 10x). (C) congestion of blood vessels with perivascular cuffing of mononuclear inflammatory cells (arrow) (H\&E 40x). (D) neurophagia (arrow) (H\&E 40x). (E) glial nodules were in the brain parenchyma (arrow) (H\&E 10x). (F) thickening of meninges with congestion of blood vessels and infiltration of inflammatory cells (H\&E 40x). (G) Alzheimer type II astrocytes, which characterized by double nuclei which surround by clear space (Arrows) (10x). 


\section{Spinal cord}

The microscopic examination of spinal cord sections showed histological alteration characterized by degenerative changes and necrotic lesions in motor neuronal cells of gray matter, and losing their dendrites, with pyknosis of nucleus, and infiltration of microglial cells. Additionally, hemorrhage also observed in the white mater and gray matter. Demyelination showed in white matter, with microglial infiltration around vertebral canal of spinal cord (Figure 3).

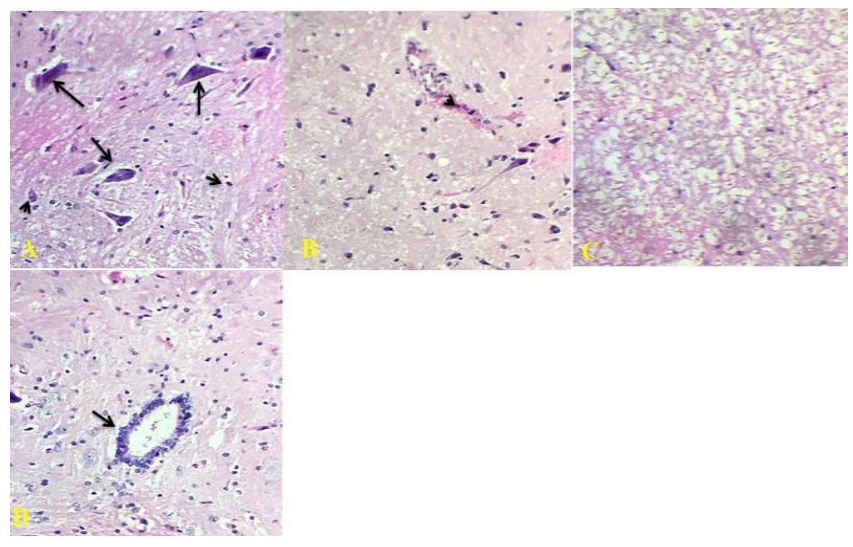

Figure 3: Micrograph of Rat Brain, treated with lead acetate (A) degenerative and necrotic lesions in motor neuronal cells of gray matter, they loss their dendrites (arrow), pyknosis of nucleus (arrowhead) (H\&E 40x). (B), hemorrhage also observed in the gray and white matter (H\&E 40x). (C) demyelination in the white matter (H\&E 40x). (D) microglial infiltration around central canal of spinal cord (arrow) (H\&E 40x).

\section{Discussion}

Lead toxicity is a metal poisoning triggered by the accumulation of lead in the tissues (10). It is a potent neurotoxic agent, affecting nervous system $(2,3)$. The brain tissue is vulnerable to the effects of lead injury $(11,12)$. Lead is capable to pass through the endothelium of the blood brain barrier because it can replace for ions of the calcium and be taken up by $\mathrm{Ca}^{+2}$-ATPase pumps, thus interfering with synapse formation. This study was conducted to assess the histopathological effects of long used of lead acetate on the central nervous tissues (Cerebrum, cerebellum and spinal cord). Histopathological changes result from exposed to lead showed cerebrum tissue degeneration and necrosis of cortical neurons with multifocal area of encephalomalacia, as well as congestion of blood vessels with perivascular cuffing of mononuclear inflammatory cells. Additionally, hemorrhage, neurophagia and glial nodules were observed. These finding are agreement with those reported by $(11,13,14)$ which they exposed mice, rats and guinea pigs to lead and observed Vascular lesions additionally to encephalpathic injury of lead mediated at the neuronal level.
Other researchers have established that lead has toxic effects on the brain of rats, inducing vascular damage in additions to parenchymal necrotic lesions and vacuolation in the hypothalamus $(8,15)$.

Histopathological examination of cerebellum and spinal cord revealed vasogenic edema, thickening of meninges with degeneration and necrosis of neurons as well as congestion of blood vessels and infiltration of inflammatory cells. Moreover, observed of Alzheimer type II astrocytes. All these finding were in agreement with other studies that described loss of neurons in different layers of cerebellum cortex, as well as degenerative and necrosis of Purkinje cells, with widening of perineuronal space $(2,16)$.

These histopathological changes in the cerebrum, cerebellum and Spinal cord could be related to oxidative stress, and the imbalance between the production of reactive oxygen species ROS and the capability of antioxidant mechanisms to deactivate them. Many of these reactive oxygen mediators lead to cellular organelles injury and reproduction of another toxic molecule.

Free radicals can trigger nuclear kappa B factor (NF- $\mathrm{kB})$; a redox-sensitive transcription factor that trigger the genes of inflammation and later reproduced of multiple inflammatory chemical mediators $(17,18)$.

Several workers estimated the possible effects of free radicals species in the inducing of lead toxicity (18-20) which cause rapid lipid peroxidation and depletion the activity of antioxidants enzymes, for example the glutathione peroxidase and superoxide dismutase of brain tissue $(21,22)$. In addition to elevated reactive oxygen species, the levels of nitric oxide were found to be increased in brain tissue (23). The degenerative and necrotic changes recorded in the neurons cerebrum, cerebellum and Spinal cord represent ischemic changes resulting from damage of blood vessels. Moreover, lead accumulates caused damages to the mitochondria. Biosynthesis, a function of neuronal mitochondrial activity, is affected by lead, with disruptive effects on the synaptic transmission in the brain. Lead also killing cells of brain by apoptosis $(4,24)$.

\section{Conclusions}

This study referred to the increased risk of central nervous system damage due to the exposure to lead.

\section{Acknowledgment}

We would like to thanks to all those who provided me the possibility to finished this article, specially College of Veterinary Medicine and Department of Biology, College of Education for Girls, University of Mosul.

\section{Conflict of Interest}

The authors declare that no conflict of interest exists. 


\section{References}

1. Jaafar RS. Bioremediation of lead and cadmium and the strive role of Pediococcus pentosaceus probiotic. Iraqi J Vet Sci. 2020;34(1):5157.Doi: 10.33899/ijvs.2019.125581.1092

2. Nagri SZ. A Comparative study of the histological changes in cerebral cortex, hippocampus, cerebellum, pons and medulla of the albino rat due to lead toxicity. Int J Anat Res. 2015;3(2):1173-1178. Doi: $\underline{10.16965 / i j a r .2015 .194}$

3. Wani L, Anjum ARA, Usmani JA. Lead toxicity: A review. Interdiscip Toxicol. 2015;8(2):55-64. DOi: 10.1515/intox-2015-0009

4. Saleh S, Meligy F. Study on toxic effects of lead acetate on cerebellar cortical tissue of adult albino rats and the role of vitamin e as a protective agent. Ain Shams J Forensic Med Clin Toxicol. 2018;31(2):110-118. Doi: 10.21608/AJFM.2018.15884

5. Ahmed MB, Ahmed MI, Meki AR, Abdraboh N. Neurotoxic effect of lead on rats: Relationship to apoptosis. Int J Health Sci. 2013;7:192-9. Doi: $10.12816 / 0006042$

6. Matović V, Buha A, DukiC CD, Bulat Z. Insight into the oxidative stress induced by lead and/or cadmium in blood, liver and kidneys. Food Chem Toxicol. 2015;78:130-140. Doi: 10.1016/j.fct.2015.02.011

7. Dewanjee S, Sahu R, Karmakar S, Gangopadhyay M. Toxic effects of lead exposure in Wistar rats: Involvement of oxidative stress and the beneficial role of edible jute (Corchorus olitorius) leaves. Food Chem Toxicol. 2013;55:78-91. Doi: 10.1016/j.fct.2012.12.040

8. Adedayo AD, Stephen AO, Adekilekun TA, Daniel AT. Lead induces inflammation and neurodegenerative changes in the rat medial prefrontal cortex. Anat. 2017;11(2):79-86. Doi: 10.2399/ana.17.015

9. Luna LG. Manual of histologic staining methods of the armed forces institute of pathology. $3^{\text {rd }}$ ed. New York: McGraw-Hill; 1968. 28-38 p.

10. Al-Naemi HS, Al-Sanjary RA, Faraj RA, Asi A. Detection of lead, chromium and cobalt in meats of cattle and buffalo from retails of Mosul city. Iraqi J Vet Sci. 2020;34(2):337-451. Doi: 10.33899/ijvs.2019.126069.1224

11. Kumar SP, Kumar SM, Singh YR, Kumar DR, Mehrotra A, Nath R. Attenuation of lead-induced neurotoxicity by omega-3 fatty acid in rats. Ann Neurosci. 2017;24:221-232. Doi: 10.1159/000481808

12. Hareeb DA, Hussien HM, Khalil AA, El-Saadani MA, Ali AN. Toxic effects of lead exposure on the brain of rats: Involvement of oxidative stress, inflammation, acetylcholinesterase, and the beneficial role of flaxseed extract. Toxicol Environ Chem. 2009;92:187-195. Doi: 10.1080/02772240902830631

13. Yun HJ, Kim I, Kwon S, Kang J, Om A. Protective effects of chlorella vulgaris against lead- induced oxidative stress in rat brains. J Health Sci 2011; 57):245-254. Doi: 10.1248/jhs.57.245

14. Bouldin TW, Krigman MR. Acute lead encephalopathy in the guinea pig. Acta Neuropathol. 1975;33(3):185-190. Doi: 10.1007/bf00688392

15. Hirano A, Kochen JA. Some effects of intracerebral lead implantation in the rat. Acta Neuropathol. 1975;30:307-15. Doi: $10.1007 / \mathrm{bf00686162}$

16. Liu JT, Chen BY, Zhang JQ, Kuang F, Chen LW. Lead exposure induced microgliosis and astrogliosis in hippocampus of young mice potentially by triggering TLR4-MyD88-NFKB signaling cascades. Toxicol Lett. 2015;239:97-107. Doi: 10.1016/j.toxlet.2015.09.015

17. Bokara KK, Brown E, McCormick R, Yallapragada PR, Rajanna S, Bettaiya R. Lead-induced increase in antioxidant enzymes and lipid peroxidation products in developing rat brain. Biometals. 2008;21:916. https://doi.org/10.1007/s10534-007-9088-5

18. Adonaylo A, Oteiza P. Lead intoxication: Antioxidant and oxidative damage in rat brain. Toxicol. 1999;135:77. Doi: 10.1016/s0300$\underline{483 x(99) 00051-7}$
19. Pande M, Flora S. Lead induced oxidative damage and its response to combined administration of -lipoic acid and succimers in rats. Toxicol. 2002;177:187-96. Doi: 10.1016/s0300-483x(02)00223-8

20. Hsu P, Guo Y. Antioxidant nutrients and lead toxicity. Toxicol. 2002;180:33-44. Doi: $10.1016 / 50300-483 x(02) 00380-3$

21. Patra RC, Rautray AK, Swarup D. Oxidative stress in lead and cadmium toxicity and its amelioration. Vet Med Int. 2011;27:18-19. Doi: 10.4061/2011/457327

22. Ghareeb DA, Hussien HM, Khalil AA, El-Saadani MA, Ali AN. Toxic effects of lead exposure on the brain of rats: Involvement of oxidative stress, inflammation, acetylcholinesterase, and the beneficial role of flaxseed extract, Toxicol Environ Chem. 2010;92(1):187-195. Doi: 10.1080/02772240902830631

23. Bauchi ZM, Kizito D, Alhassan AW, Akpulu SP, Timbuak JA. Effect of aqueous seed extract of Nigella sativa on lead-induced cerebral cortex toxicity in long evans rats. Bayero J Pure Appl Sci. 2016;9(1):4852. Doi: $10.4314 /$ bajopas.v9i1.8

24. Adekomi DA, Stephen AO, Adekilekun TA, Daniel AT. Lead induces inflammation and neurodegenerative changes in the rat medial prefrontal cortex. Anat. 2017;11(2):79-86. Doi: 10.2399/ana.17.015
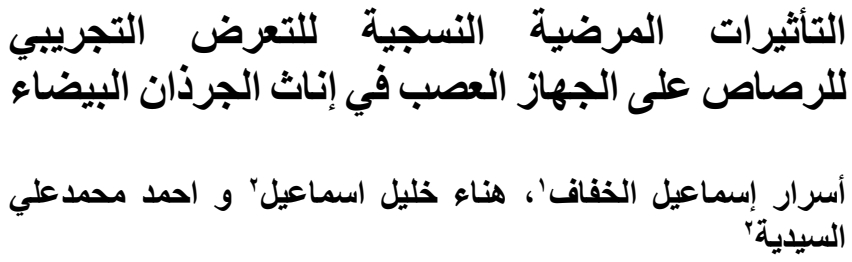

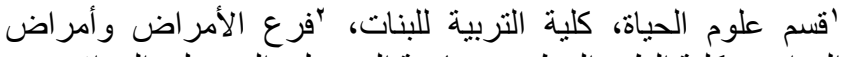
الدو اجن، كلية الطب البيطري، جامعة الموصل، الموصل، العراق

الخلاصة

تعد سمية الرصاص مشكلة صحية عامة في جميع أنحاء العالم، حيث

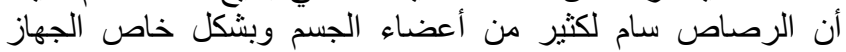

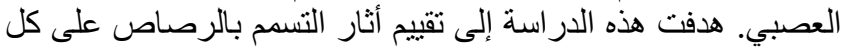

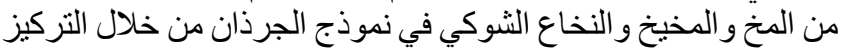

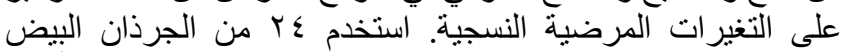

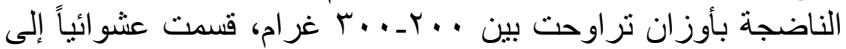

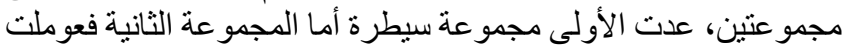

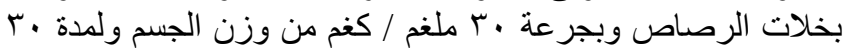

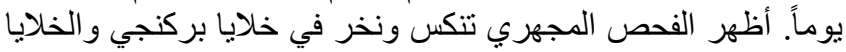
الجزيئية مع وجود تناقص في خلايا بيركنجي في الطبقة فئي الحبيبية و الجزيئية ولوحظ احتقان للأوعية الدموية مع تكفف للخية لخائيا الالتهابية

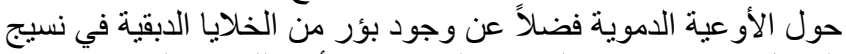

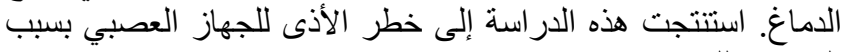
التعرض للرصاص. 
- A.I. Al-Khafaf, asraralkhafaf7@gmail.com

- H.Kh. Ismail hana_khismail@yahoo.com Orchid https://orcid.org/0000-0002-3485-320X

- A.M. Al-Saidya al2011saidya@gmail.com https://orcid.org/0000-0003-0730-6929

, email: ${ }^{1} \underline{\text { asraralkhafaf7@gmail.com }}{ }^{2} \underline{\text { hana_khismail@yahoo.com }}{ }^{3}$ al2011saidya@gmail.com

\section{Highlights}

Increased risk of central nervous tissue damage due to the exposure to lead, in the Cerebellum, Cerebrum and spinal cord. 